\title{
Present Biological Status of Potential Medicinal Plant of Amaranthus viridis: A Comprehensive Review
}

\author{
Md. Reyad-ul-Ferdous ${ }^{1,2,3,{ }^{*} \text {, D. M. Shamim Shahjahan }{ }^{2} \text {, Sharif } \text { Tanvir }^{2} \text {, Mohsina Mukti }}{ }^{3}$ \\ ${ }^{1}$ Department of Pharmacy, Progati Medical Institute, Dhaka1216, Bangladesh \\ ${ }^{2}$ Department of Pharmacy, State University of Bangladesh, Dhaka-1205, Bangladesh \\ ${ }^{3}$ Department of Pharmaceutical Sciences, North South University, Dhaka1229, Bangladesh
}

Email address:

rockyreyad@yahoo.com (Md. Reyad-ul-Ferdous)

\section{To cite this article:}

Md. Reyad-ul-Ferdous, D. M. Shamim Shahjahan, Sharif Tanvir, Mohsina Mukti. Present Biological Status of Potential Medicinal Plant of Amaranthus viridis: A Comprehensive Review. American Journal of Clinical and Experimental Medicine. Special Issue: Herbal Remedies as Alternative to Future Drugs Development and Treatment. Vol. 3, No. 5-1, 2015, pp. 12-17. doi: 10.11648/j.ajcem.s.2015030501.13

\begin{abstract}
Amaranthus viridis L. belongs to family (Amaranthaceae) commonly known as "Chowlai" is a common wild vegetable and weed of cultivation. A. viridis contains several compounds like amino acids lysine, arginine, histidine, cystine, phenylalanine, leucine, isoleucine, valine, threonine, methionine, tyrosine etc. In search of new activities chemical entities, pytochemical screening of the extract from leaves of $A$. vilidis $\mathrm{L}$. indicates the presence of biologically active constituent: saponins, tannins and phenols, flavonoids, alkaloids, cardiac glycoside, steroid and triterpenoids. A. vilidis L have some chemical constituent that exhibits potent anti-inflammatory, antihepatotoxic, antiulcer antiallergic, antiviral actions. A. viridis used in Indian and Nepalese traditional system to reduce labour pain and act an antipyretic. The Negritos of the Philippines apply the bruised leaves directly to eczema, psoriasis and rashes etc. Other traditional uses range from an anti-inflammatory agent of the urinary tract, venereal diseases vermifuge, diuretic, anti-rheumatic, antiulcer, analgesic, antiemetic, laxative, improvement of appetite, antilep-rotic, treatment of respiratory and eye problems, to treatment of asthma.
\end{abstract}

Keywords: Amaranthus viridis, Pharmacologicals, Pytochemicals, Anti-inflammatory, Antinociceptive, Hepatoprotective, Antihyperglycemic, Antidiabetic, Cardio Protective, Antihyperlipidemic

\section{Introduction}

Amaranthus viridis L. (Family Amaranthaceae) is distributed in the warmer parts of the world .In addition the whole plant possesses analgesic and anti-pyretic properties and is used for the treatment of pain and fever respectively in traditional systems of medicine [1]. A. viridis is possibly of Asian origin but now a cosmopolitan weed in the tropical and subtropical regions of the world, also ubiquitous faraway to temperate regions (e.g. in Europe, North America, Asia and Australia). In equatorial Africa it is also a profound and common weed. It is occasionally cultivated (e.g. in Nigeria, Gabon and DR Congo) [2]. A. viridis Linn. Is Erect or ascending annual or short-lived perennial herb up to $1 \mathrm{~m}$ tall; glabrous, angular, bear branches, stem slender to sparsely pubescent in upper part with multicellular hairs. It is consists of alternate leaves with petiole which can be up to $10 \mathrm{~cm}$ long; blade deltoid-ovate to rhomboid-oblong, 2-8 cm $\times 1.5$ $6 \mathrm{~cm}$, margin sometimes sinuate, apex emarginate with small mucro, , base shortly cuneate, glabrous to pubescent. It also consists of axillary or mostly terminal spikes, frequently paniculated, agglomerated cymes arranged in slender, up to $12 \mathrm{~cm}$ long, in the lower part of the stem often in proliferated axillary clusters $7 \mathrm{~mm}$ in diameter. Flowers are subsessile, green in colour, unisexual, bracts and bracteoles lanceolateovate, male and female intermixed but female ones more numerous in $1 \mathrm{~mm}$ long, oblong to obovate in 1-1.5 $\mathrm{mm}$ long, whitish-membranous; tepals male flowers with 3 stamens; female flowers with superior, midrib often thickened above, bent along the fruit. Fruit of a subglobose capsule, c. $1.5 \mathrm{~mm}$ in diameter, not or slightly exceeding the perianth, usually strongly wrinkled, indehiscent, 1 seeded Seed sub globose ,slightly compressed, c. $1 \mathrm{~mm}$ in diameter, glossy black, margin acute, verrucose or with inconspicuous structure. Epigeal germination is seen in seedlings, cotyledons lanceolate, c. $12 \mathrm{~mm} \times 2.5 \mathrm{~mm}$ [2]. Leaves 
directly used to eczema, psoriasis and rashes etc [3]. Other traditional uses range from an anti-inflammatory agent of the urinary tract, diuretic, venereal diseases vermifuge, analgesic, anti-rheumatic, antiulcer, antiemetic, improvement of appetite, laxative, anti lep-rotic, treatment of respiratory, eye problems and treatment of asthma [4,5]. Furthermore, the plant possesses anti proliferative and antifungal lactin properties as well as ribosome inactivating protein, $\beta$ carotene [6,7] and antiviral activities [8]. However, there is not enough scientific reports to sup-port these supposed analgesic and antipyretic activities. This has initiated step to conduct the studies to ascertain the authenticity of these important claims of traditional potency [9].

\section{Pharmacological Activities and Medicinal Uses of $A$. viridis}

Plants are the major sources of drugs or molecule which demonstrate mild to significant pharmacological activity against tremendous organisms and diseases. Phytoconstituents and pharmacological activity demonstrate in the table-1 and table-2.

A. viridis L (Amaranthaceae) is commonly used the India and Nepal to lessen labor pains and as an antipyretic (Kirithikar and Basu, 1986; Mark Turin, 2003). The Negritos of the Philippines apply the bruised leaves directly to eczema, psoriasis and rashes (Eduardo and Quisumbing, 1951). Other traditional uses are as an anti-inflammatory agent of the urinary tract, in venereal diseases, as a vermifuge, diuretic, antirheumatic, antiulcer, analgesic, antiemetic; laxative, for improving appetite, as an antileprotic, for the treatment of respiratory problems, eye treatment and for asthma (Anonymous, 1988; Agra et al., 2007; 2008; Kirithikar and Basu, 1986; Hassan Sher and Khan, 2006; Quershi et al., 2008; Muhammad Arshad, 2000; Muhammad Ejaz Ul Islam Dar, 2003; Muhammad and Amusa, 2005) A novel antiproliferative and antifungal lactin and a ribosome inactivating protein, $\beta$-carotene, were isolated from $A$. viridis (Kaur et al., 2006; Kwon et al., 1997; Sena et al., 1998) and it also possesses antiviral activity (Obi et al., 2006). The whole of the $A$. viridis plant is used for the treatment of pain and fever in traditional medicine. However, there is insufficient scientific proof regarding the analgesic and antipyretic activity of $A$. viridis, so our aim is to provide scientific validation for traditional uses [9].

\section{Antinociceptive and Antipyretic Activities of Amaranthus Viridis}

Plants are used as antipyretic and anti-nociceptive by the following ways of methanolic extract of whole plant of $A$. viridis $\mathrm{L}$ (MEAV), was screened for anti-nociceptive activity using acetic acid induced hot plate test, writhing test and tail immersion test in mice. A screening exercise was carried out to determine the antipyretic potential of the extract using yeast induced pyrexia method in rats. The extract was administered to both laboratory animals at the doses of 200 and $400 \mathrm{mg} / \mathrm{kg}$ body weight, respectively. The statistical analysis demonstrate that MEAV had significant $(\mathrm{p}<0.01)$ dose dependent antinociceptive and antipyretic properties at 200 and $400 \mathrm{mg} / \mathrm{kg}$. Therefore, current study discloses the antinociceptive and antipyretic activities of methanolic extract of $A$. viridis [9].

\section{Antioxidant and Antimicrobial Activities of $\boldsymbol{A}$. viridis}

The present study was conducted to evaluate the phenolics, antimicrobial and antioxidant properties of leaf and seed extracts from an edible herb namely $A$. viridis $\mathrm{L}$. The extract yields of active components, produced using aqueous and pure methanol, from the seeds and leaves ranged from 2.4 to $3.7 \%$ and 5.4 to $6.0 \%$, respectively. The extracts posses significant levels of total phenolic contents (1.03 to 3.64 GAE, g/100 g) and total flavonoid contents (18.4 - 5.42 QE, $\mathrm{g} / 100 \mathrm{~g}$ ) and also exhibited good 1, 1-diphenyl-2picrylhydrazyl (DPPH) radical scavenging activity as revealed by IC50 $(14.25-83.43 \mu \mathrm{g} / \mathrm{ml})$. Besides, the tested extracts showed considerable antimicrobial activity against selected bacterial and fungal strains with minimum inhibitory concentrations (MIC) ranging from 179-645 $\mu \mathrm{g} / \mathrm{ml}$. Amongst the plant parts tested and the seed extracts exhibited superior antioxidant and antimicrobial activity. In conclusion, A. viridis leaf and seed can be explored as a potential source for isolation of antioxidant and antimicrobial agents for uses in functional food and pharmaceuticals $[10,11,12]$.

\section{Hepatoprotective Activity of $\boldsymbol{A}$. viridis}

Heaptoprotective activity of methanolic extract of whole plant of $A$. viridis Linn (MeAv) in paracetamol (PCM) induced hepatotoxicity. MeAv was screened for hepatoprotective activity in PCM $(3 \mathrm{~g} / \mathrm{kg})$ induced hepatotoxicity in Wistar rats for 15 days at dose of 200 and $400 \mathrm{mg} / \mathrm{kg}$ by measuring liver marker enzymes (serum glutamate pyruvate transaminase and serum glutamate oxaloacetate transaminase), bilirubin (total bilirubin and direct bilirubin) and albumin (ALB), total protein (TP) levels and histopathological studies. Antioxidant properties were investigated by measuring malondialdehyde (MDA), reduced glutathione (GSH), catalase (CAT) and total thiols (TT) in liver homegenate of treated animals. MeAv significantly $(\mathrm{P}<0.001)$ decreases the elevated liver marker enzymes (serum glutamate pyruvate transaminase and serum glutamate oxaloacetate transaminase), bilirubin (total bilirubin and direct bilirubin) and restores albumin (ALB), total protein (TP) levels. A histopathological study also showed liver protective property of MeAv. In animal model, the antioxidant studies, the MeAv has notably retained the malondialdehyde (MDA), reduced glutathione (GSH), catalase (CAT) and total thiols. In conclusion, administration of MeAv for 15 days showed liver protective activity against 
paracetamol induced liver damage and the potential antioxidant property of MeAv thought to be the mechanism behind its hepatoprotective activity [11].

\section{Anti-inflammatory Effects of $\boldsymbol{A}$. viridis}

The present study was carried out to investigate the antiinflammatory property of petroleum ether, alcoholic and aqueous extracts of $A$. viridis Linn leaves using experimental animal models (Male albino rats, weighing 150-200g). The Anti-inflammatory activity of the various extracts was studied based on their effects on carrageen an-induced paw oedema and cotton pellet glaucoma in rats. The extracts in dose levels of 50,100 and $200 \mathrm{mg} / \mathrm{kg}$ orally applied for antiinflammatory studies. The aqueous and ethanol extracts of leaves of trianthema portulacastrum significant $(\mathrm{P}<0.05)$ antiinflammatory activities in a dose-dependent manner to that of standard drug indomethacin, where as petroleum ether extract exhibit minimum inhibitory effect in carageenan induced hind paw oedema and cotton pellet granuloma in rats. All the doses were applied relative to the control group. The crude leaf extracts demonstrate of $A$. viridis possess potent antiinflammatory by supporting the folkloric usage of the plant to treat various inflammatory conditions [13].

\section{Antihelmintic Activity of $\boldsymbol{A}$. viridis}

According to the WHO, only a few drugs are used in treatment of helminthes in humans. Anthelmintics from plant resources play a key role in the treatment of these parasite infections. In view of this, attempts have been made to study the anthelmintic activity of traditional medicinal plants. The three plants presented in this study are Amaranthus viridis L., Amaranthus spinosus and Amaranthus caudatus. They belong to the Amaranthaceae family and are traditionally used as vermicides. Our aim was to investigate the anthelmintic activity of the three plants using earthworms (Pheretima posthuma). Methanol extracts of the three plants at different concentrations $(10,20,40,60,80,100 \mathrm{mg} / \mathrm{ml})$ showed dose-dependent vermicidal activities. At concentrations of 80 and $100 \mathrm{mg} / \mathrm{ml}$ all three plant extracts caused paralysis $(8.18,5,12.16,5.75,10.2,7.8 \mathrm{~min})$ and death $(14.65,9.12,18.6,8.5,18.6,12.7 \mathrm{~min})$, respectively. Piperazine was applied as a reference standard at a concentration of $10 \mathrm{mg} / \mathrm{ml}$. Our study found that the three plants possess potent anthelmintic activity when compared to Piperazine [14].

\section{Antifungal Activity of $A$. viridis}

The plants have investigated in the search for new substances against microorganisms resistant to current pesticides and antibiotics. They are evaluate the existence of antiphytopathogenic properties of organic extracts from the leaves of amaranth (A. viridis L.), Amaranthaceae, popularly known as caruru. The hexanic, dichloromethanic, ethylic acetate and ethanolic extracts were obtained, respectively with yields of 2.2, 2.4, 3.2 and $3.6 \%(\mathrm{~m} / \mathrm{m})$. These extracts were used to determine the Minimum Inhibitory Concentration (MIC), through dilution technique using 96 well microplate. After investigating the CIM in wells where no fungal growth was detected, the Minimum Fungicidal Concentration (MFC) was determined on plates containing dextrose Sabouraud agar. The experimental crude extracts of Amaranthus indicate activity against the fungi Colletotrichum musae (Berk. and Curt.) Arx, causing anthracnose of banana and against Fusarium solani f. sp. piperis responsible for fusariosis in black pepper. In comparison to Colletotrichum musae extracts obtained with ethyl acetate, dichloromethane and ethanol, the MIC differ from 15.6-250.0 $\mu \mathrm{g} \mathrm{mL}^{-1}$. The ethylic acetate, hexanic and ethanolic extracts showed activity against Fusarium solani with MIC limited from 31.2-250.0 $\mu \mathrm{g} \mathrm{mL}^{-1}$. In this research, it was showed the presence of antifungal constituents in extracts of $A$. viridis L., revealing its potential antimicrobial effect against these two phytopathogenic strains tested [15].

\section{Antihyperglycemic and Hypolipidemic Activity of $A$. viridis}

To investigate the hypolipidemic and antihyperglycemic effects of methanolic extract of leaves of A. viridis (MEAV) in normal and Streptozotocin (STZ) induced diabetic rats. The activities of methanol extract of leaves of A. viridis was evaluated by using normal and STZ induced diabetic rats at dose of $200 \mathrm{mg} / \mathrm{kg}$ and $400 \mathrm{mg} / \mathrm{kg}$ by mouth per day for 21 days. Body weight and blood glucose levels were monitored at specific intervals, and different biochemical parameters such as serum triglyceride, serum cholesterol high density lipoprotein, and low density lipoprotein were assessed. Very low density lipoprotein, were also evaluated in the experimental animals. Histology of pancreas was performed. The statistical data demonstrated a significant increase in the body weight, decrease in the serum triglycerides, total cholesterol and blood glucose after treatment with MEAV. High density lipoprotein (HDL) cholesterol level was significantly increased when treated with extract. In histological study, focal necrosis was found in the diabetic rat pancreas; however, was less profound in treated groups. The MEAV has advantageous impact in reducing the elevated blood glucose level and body weight changes, and in STZ induced rats, the lipid profile is improved.

According to the International Diabetes federation (IDF), at present Type-2 diabetes affects 246 million people worldwide and is expected to increase to 380 million by 2025 . Metabolic syndrome is a amalgamation of various disorders, including reduced glucose tolerance, abdominal obesity, high cholesterol and high blood pressure which enhance the risk of diabetes and cardiovascular disease.

Recent studies have demonstrated a variety of important literature indicates that there is no scientific evidence to support the antihyperglycemic and hypolipidemic effects of A. viridis. The present study investigates the action of 
methanolic extract of A.viridis (MEVA) in the different models of rats to ascertain the scientific basis for the use of this plant in the treatment of diabetes and hyperlipidemia [16].

\section{Antioxidant, Antihyperlipidemic and Antidiabetic Activities of $\boldsymbol{A}$. viridis}

The antioxidant, antihyperlipidemic and antidiabetic activities of methanolic extract of whole plant of $A$. viridis (MEAV) in alloxan (ALX) induced diabetic rats. Diabetes was diagnosed after 5 days of single intraperitoneal injection of ALX (140 mg/kg) in albino Wister rats. MEAV (200 and $400 \mathrm{mg} / \mathrm{kg})$ and glibenclamide $(10 \mathrm{mg} / \mathrm{kg}$, p.o.) orally ingested everyday for 15 days, blood was withdrawn for glucose level determination on $0,1,10$ and 15 days respectively. In the day 15, rats were fasted overnight, sacrificed and blood was collected for the determination of high density lipoproteins cholesterol (HDL-C), low density lipoprotein cholesterol (LDL-C), very low density lipoprotein cholesterol (VLDL-C), total cholesterol (TC), total glycerides (TG) and total proteins (TP). For in vivo antioxidant activity of MEAV, the assay of lipid peroxidation and liver tissues were homogenized was measured as glutathione (GSH), Malondialdehyde (MDA), catalase (CAT) and total thiols (TT) were performed in, ALX, MEAV treated and control rats. MEAV at doses of 200 and $400 \mathrm{mg} / \mathrm{kg}$ showed significant reduction is lipid profiles and blood glucose including significant improvement in TT, CAT, GSH, and MDA when compared to diabetic control group. Ex vivo $\alpha$-amylase inhibition activity of MEAV was investigated. We can conclude that MEAV possess antioxidant, antihyperlipidemic and antidiabetic activities $[12,11,17,10]$.

Table 1. Presenting various chemical constituents of plant $A$. viridis $L$.

\begin{tabular}{lll}
\hline Chemical Compound & Parts & References \\
\hline Tannin & Leaves & 1 \\
Resin & Leaves & 1 \\
Reducing Sugar & Leaves & 1 \\
Phlobatannins & Leaves & 10 \\
Flavonoids & Leaves & 10 \\
Cardiac glycosides & Leaves/seeds & 10 \\
Protein & Leaves & 18 \\
Linoleic acid & Leaves & 18 \\
$\alpha$ - Linoleic acid & Leaves & 18 \\
Iron & Leaves & 18 \\
Magnesium & Leaves & 18 \\
Calcium & Leaves & 18 \\
Zinc & Leaves & 18 \\
Amasterol & Root & 19 \\
Saponins & Seeds & 20 \\
Pentatriacontane & Seeds & 20 \\
Hexatriacontane & Seeds & 20 \\
Triacontane & Seeds & 20 \\
6-Pentatriacontane & Seeds & 20 \\
Hentriacontane & Seeds & 20 \\
Ecdysterone & Seeds & 20 \\
Oxalic acid & Wild edible plants & 21 \\
Carotenoids & Wild edible plants & 21 \\
$\beta$-Carotene & Leaves & 22 \\
\hline
\end{tabular}

Table 2. Presenting various pharmacological activities attributed to plant A. viridis.

\begin{tabular}{ll}
\hline Activity & References \\
\hline Antioxidant & $10,11,12$ \\
Antimicrobial & 10 \\
Anti-inflammatory & 13 \\
Antinociceptive & 9 \\
Antipyretic & 9,1 \\
Antihelmintic & 14 \\
Antifungal & 15 \\
Hepatoprotective & 11 \\
Antihyperglycemic & 16 \\
Hypolipidemic & 16 \\
Antidiabetic & 12,17 \\
Antihyperlipidemic & 12 \\
Antiviral & 8 \\
Cardio protective & 23 \\
\hline
\end{tabular}

Classification: Amaranthus viridis [24]

Kingdom: Plantae

Subkingdom: Tracheobionta

Superdivision: Spermatophyta

Division: Magnoliophyta

Class: Magnoliopsida

Subclass: Caryophyllidae

Order: Caryophyllales

Family: Amaranthaceae

Genus: Amaranthus L.

Species: Amaranthus viridis L.

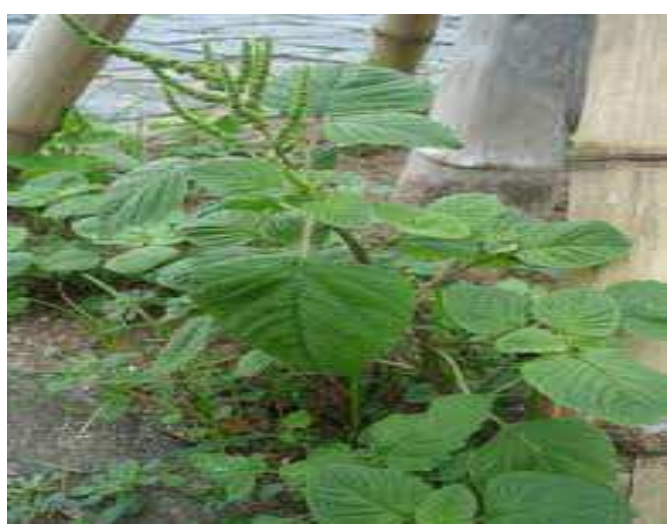

Fig. A. Adult tree.

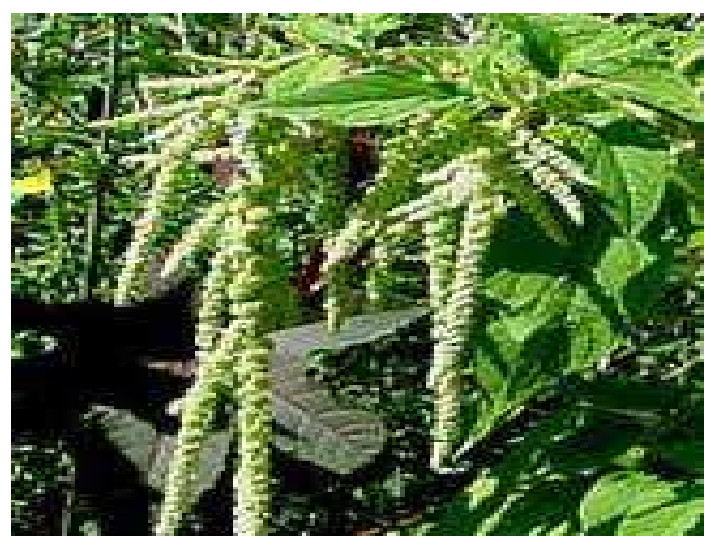

Fig. B. flowering tree. 


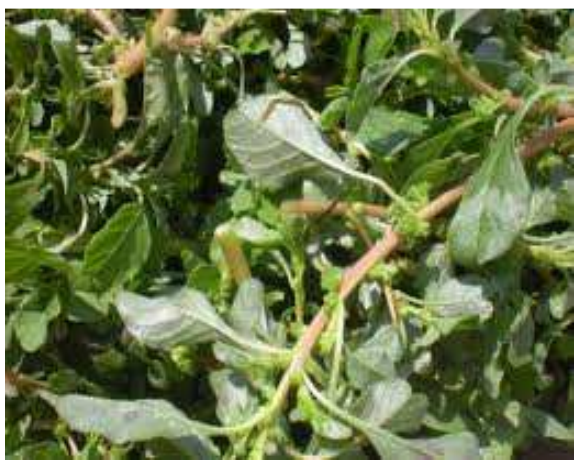

Fig. C. Stem.

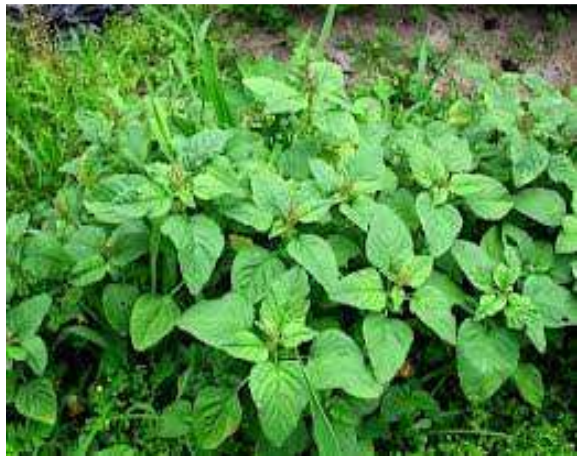

Fig. D. Leaf.

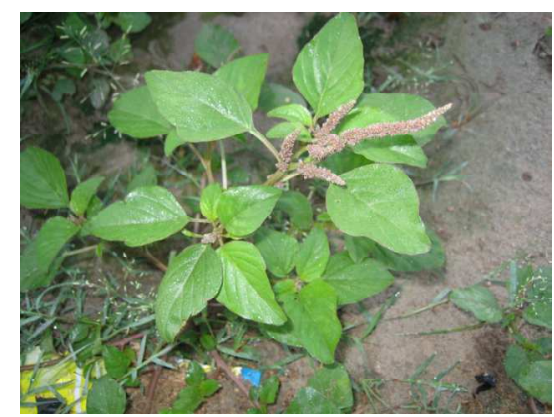

Fig. E. Whole tree

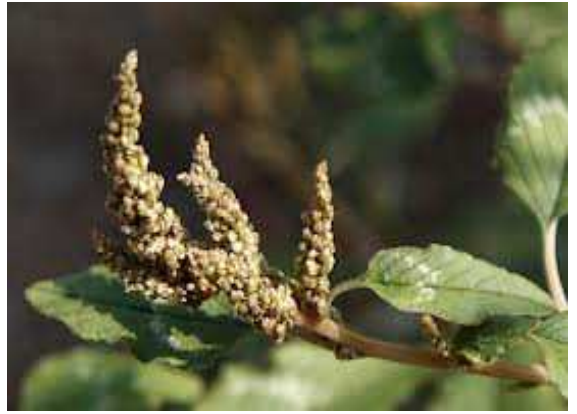

Fig. F. Flower.

\section{References}

[1] ELUWA, M. C.. Studies on G. rhomboidalis (Boheman) (coleoptera: Curculionidea), a pest of African spinach. Journal of Natural History, 1977;11: 417 - 424.

[2] Brenan, J.P.M. The genus Amaranthus in southern Africa. Journal of South African Botany. 1981;47: 451-492.
[3] Kiritikar KR, Basu BD. Indian Medicinal Plants. Vol. 3. 2nd ed. In: Kirtikar KR, Basu BD (eds). Dehra Dun, India: International book distributors; 1987, 2061-2062.

[4] Council of Scientific and Industrial Research (CSIR). Publications and Information Directorate. The Wealth of India. Vol. 1. A Dictionary of In-dian raw materials and industrial products. New Delhi, India: 1988. 221 p.

[5] Agra MF, Baracho GS, Nurit K, Basilio IJLD, Coelho VPM. Medicinal and poisonous diversity of the flora of "Cariri Paraibano" Brazil. J Ethno-pharmacol 2007; 111(2):283-395.

[6] Sena LP, Vanderjagt DJ, Rivera C, Tsin ATC, Muhamadu I, Mahamadou $\mathrm{O}$, et al. Analysis of nutritional components of eight famine foods of the Republic of Nigeria. Plant Foods Hum Nutr 1998; 52(1):17-30.

[7] Gallagher, R. S., \& Cardina, J.. Phytochrome-mediated Amaranthus germination I: Effect of seed burial and germination temperature. Weed Sci.1998; 46, 48-52.

[8] M. B. Nordeide, A. Hatløy, M. Følling, E. Lied and A. Oshaug, Nutrient composition and nutritional importance of green leaves and wild food resources in an agricultural district, Koutiala, in Southern Mali. 1996; 47(6) , 455-468 .

[9] Bagepalli Srinivas Ashok Kumar, Kuruba Lakshman , Korala Konta Narsimha Jayaveera, Devangam Sheshadri Shekar, Chinna SwamyVel Muragan, and Bachappa Manoj , Antinociceptive and Antipyretic Activities of Amaranthus Viridis Linn in Different Experimental Models. Avicenna Journal of Medical Biotechnology.2009;1(3): 167-171.

[10] Muhammad Javid Iqbal, Sumaira Hanif, Zahed Mahmood, Farooq Anwar and Amer Jamil Antioxidant and antimicrobial activities of Chowlai (Amaranthus viridis L.) leaf and seed extracts. Journal of Medicinal Plants Research. 2012; 6(27), 4450-4455.

[11] Ashok Kumar BS, Lakshman K, Narayan Swamy VB, Arun Kumar PA, Sheshadri Shekar D, Manoj B, Vishwantha GL Hepatoprotective and Antioxidant Activities of Amaranthus viridis Linn. Macedonian Journal of Medical Sciences. 2011 Jun $\quad 15 ; \quad 4(2): 125-130$ doi:10.3889/MJMS.18575773.2011.0163 Basic Science.

[12] Ashok Kumar BS, Lakshman K, Jayaveea KN, Sheshadri Shekar D, Saleemulla Khan, Thippeswamy BS, Veerapur VP Antidiabetic, antihyperlipidemic and antioxidant activities of methanolic extract of Amaranthus viridis Linn in alloxan induced diabetic rats. 2012; 64(1-2):75-79.

[13] Sravan Prasad Macharla,Venkateshwarlu Goli, K Vijaya Bhasker, P. Suvarna Devi Ch. Dhanalakshmi, Ch. Sanjusha, Effects of anti-inflammatory activity of Amaranthus viridis Linn. Scholars Research Library Annals of Biological Research, 2011, 2 (4): 435-438.

[14] Ashok Kumar, B.S, lakshman, K.,jayaveera, K.N., Nandeesh, R., Manoj, B. and Ranganayakulu, D ,Comparative in vitro Anthelmintic Activity of Three Plants From The Amaranthaceae Family. Arch. Biol. Sci., Belgrade. 2010;62(1),185-189. DOI:10.2298/ABS1001185K .

[15] Bruna Carminate, Giordano Bruna Martin,Roney Martinho Barcelos,Ivoney Gontijo,Marcelo Suzart de Almeida,Valdenir Jose Belinelo Evaluation of Antifungal Activity of Amaranthus viridis L. (Amaranthaceae) on Fusariosis by Piper nigrum L. and on Anthracnose by Musa sp. Agricultural Journal. 2012; 7(3):215-219. 
[16] Girija Krishnamurthy, Kuruba Lakshman, Nagaraj Pruthvi, and Pulla Udaya Chandrik Department of Pharmacognosy, Peoples Educational Society, College of Pharmacy, Bangalore - 560 050, Karnataka, India.Correspondence to: Dr. K. Lakshman,

E-mail:

drlakshman26@rediffmail.comAntihyperglycemic and hypolipidemic activity of methanolic extract of Amaranthus viridis leaves in experimental diabetes, Indian J Pharmacol. 2011; 43(4): 450-454.

[17] Girija K, Lakshman K, Udaya Chandrika, Sabhya Sachi Ghosh, Divya T. Anti-diabetic and anti-cholesterolemic activity of methanol extracts of three species of Amaranthus. Asian Pac J Trop Biomed. 2011;1(2):133-8. doi:10.1016/S2221-1691(11)60011-7.

[18] Sena LP, Vanderjagt DJ, Rivera C, Tsin AT, Muhamadu I, Mahamadou O, Millson M, Pastuszyn A, Glew RH, Analysis of nutritional components of eight famine foods of the Republic of Niger. Plant Foods Hum Nutr. 1998; 52(1):17-30.

[19] Brenan, J.P.M.. The genus Amaranthus in southern Africa. Journal of South African Botany . 1981; 47: 451-492.

[20] Musharaf Khan, Shahana Musharaf, Mohammad Ibrar and
Farrukh Hussain Pharmacognostic evaluation of the Amaranthus viridis L Research in Pharmaceutical Biotechnology. 2011; 3(1), 11-16.

[21] Hamid Kheyrodin, Isolation and identification of new eleven constituents from medicinal plant. International Journal of Nutrition and Metabolism. 2009; 1(2) 014-0191.

[22] Muhammad Islam, Ejaz Ali, Muhammad Asif Saeed, Muhammad Jamshaid and Muhammad Tahir Javed Khan. Antimicrobial and irritant activities of the extracts of Malva parviflora L., Malvastrum coromandelianum L. AND Amaranthus viridis L. -A preliminary investigation, 42.Pak. J. Pharm. 20-23 (1 \& 2), 3-6, 2007-2010 ISSN: 1019-956X.

[23] G Saravanan, P Ponmurugan, M Sathiyavathi, S Vadivukkarasi, S Sengottuvelu, Cardioprotective activity of Amaranthus viridis Linn: Effect on serum marker enzymes, cardiac troponin and antioxidant system in experimental myocardial infarcted rats. Int J Cardiol. 2013; 25;165(3):494-8. doi: 10.1016/j.ijcard.2011.09.005.

[24] Kaur N, Dhuna V, Kamboj SS, Agrewala JN, Singh J. A novel antiproliferative and antifungal lectin from Amaranthus viridis Linn seeds. Protein Pept Lett. 2006; 13(9):897-905. 